\title{
Sinopse do gênero Phyllanthus (Phyllanthaceae) NO NORDESTE DO BRASIL
}

\author{
Marcos José da Silva ${ }^{1,3}$ \& Margareth Ferreira de Sales ${ }^{2}$
}

\begin{abstract}
Resumo
(Sinopse do gênero Phyllanthus (Phyllanthaceae) no Nordeste do Brasil) Este trabalho foi baseado na análise de materiais de herbário, documentações bibliográficas e coletas, revelando a ocorrência de 36 espécies do gênero Phyllanthus na Região Nordeste do Brasil. Parte destas espécies tem distribuição no domínio do semi-árido, estando oito delas dispersas na porção centro-sul da Bahia, quatro são mais comuns no Nordeste oriental e nove têm distribuição principalmente na faixa litorânea, na Floresta Atlântica. As demais espécies são amplamente distribuídas. É fornecida chave para identificação das espécies e comentários sobre distribuição geográfica e hábitats. Palavras-chave: Phyllatheae, diversidade, distribuição geográfica, taxonomia.
\end{abstract}

\section{Abstract}

(Synopsis of the genus Phyllanthus (Phyllanthaceae) from Northeastern Brazil) This work was based on the analysis of the herbarium material, specialized bibliography and field-collections, recording the occurrence of 36 species of the genus Phyllanthus. Some species of Phyllanthus show distribution in the semi-arid region, with eight species dispersed in the central Southern part of Bahia, four species commonly found in the Eastern part of Northeastern Brazil, and nine species of the genus mainly distributed in the coastal area, in association with the atlantic forest. Other species have a wide ranging distribution. A key to identify the species together with comments about their distribution and habitat is provided.

Key words: Phyllantheae, diversity, geographical distribution, taxonomy.

\section{INTRODUÇÃo}

Os estudos filogenéticos de Wurdack (2002) e Chase et al. (2002), baseados na análise de DNA, comprovaram ser Euphorbiaceae s.l. polifilética e deram suporte ao seu desmembramento em três famílias: Euphorbiaceae s.s., incluindo espécies uniovuladas e Phyllanthaceae e Picrodendraceae, reunindo espécies biovuladas. Phyllanthaceae é monofilética e uma das famílias mais diversificadas da ordem Malpighiales (clado Eurosidae I), com aproximadamente 2.000 espécies, arranjadas em 59 gêneros de distribuição cosmopolita (Chase et al. 2002; Samuel et al. 2005).

Phyllanthus é o maior gênero de Phyllanthaceae e um dos mais diversificados dentre os gêneros de Angiospermas com aproximadamente 1.269 espécies distribuídas pelo globo (Webster 2002b; Kathriarachchi et al. 2006). Dentre os países do novo mundo, o Brasil se destaca com cerca de 107 espécies, sendo citadas 200 espécies para o neotrópico
(Webster 2002b). No Brasil, representantes de Phyllanthus são encontrados em todos os tipos vegetacionais, especialmente nas formações abertas (Silva \& Sales 2004, 2007).

Tratamentos sistemáticos para Phyllanthus incluindo subgêneros, seções e subseções, foram realizados por diversos autores: Mueller (1866, 1873), Rossignol et al. (1987), Webster (1955, 1956, 1957, 1958, 2001, 2002ab, 2003) e Santiago et al. (2006). Mesmo assim, não existe, na atualidade, uma classificação para todo o gênero. Entretanto, com base nos trabalhos supracitados pode-se sintetizar a classificação infragenérica de Phyllanthus em 10 subgêneros e cerca de 50 seções.

Pouco se sabe sobre a taxonomia das espécies brasileiras deste gênero. Descrições e comentários de algumas delas são encontradas em Mueller (1873), Cordeiro (1992), Ulysséa \& Amaral (1997), Smith \& Downs (1959) e Santiago et al. (2006). Destes, o estudo de Mueller (1873), embora

Artigo recebido em 11/2007. Aceito para publicação em 04/2008.

${ }^{1}$ Universidade Estadual de Campinas/UNICAMP, Instituto de Biologia, Departamento de Botânica, C.P. 6109, 13083-970, Campinas, SP, Brasil.

${ }^{2}$ Universidade Federal Rural de Pernambuco, Departamento de Biologia, Área de Botânica, Rua Dom Manoel de Medeiros s/n, 52171-900, Dois Irmãos, Recife, PE, Brasil.

${ }^{3}$ Autor para correspondência: marcos_agrorural@hotmail.com 
desatualizado, é o mais completo por abranger 73 espécies. Se no Brasil o conhecimento sobre Phyllanthus é escasso e disperso na literatura, este agrave é ainda maior na Região Nordeste, onde o gênero é mencionado apenas nos estudos de Cordeiro (1995), Carneiro-Torres et al. (2003) e os de Silva \& Sales (2004, 2007).

Considerando a expressividade de Phyllanthus na flora do Brasil, o elevado número de espécimes encontrados sem identificação nos herbários nordestinos e a complexidade morfológica do gênero, este trabalho visa fornecer subsídios para a identificação das espécies de Phyllanthus ocorrentes no Nordeste do Brasil e comentários sobre morfologia, distribuição geográfica e hábitats preferenciais das mesmas.

\section{Material e Métodos}

Este estudo baseou-se, principalmente, no levantamento de espécimes depositados nos herbários: ALCB, EAC, EAN, ESA, CEPEC, CPATSA, CTES, G, HAS, HB, HRB, HRCB, HUEFS, IBGE, INPA, IPA, JPB, K, MBM, NY, PACA, PEUFR, PMSP, R, RB, RSPF, SJRP, SP, SPSF, TEPB, UB, UEC, UFP, US e VIC (acrônimos segundo Holmgren et al. 1990) e, em extensa revisão bibliográfica, além de coletas efetuadas em Alagoas, Bahia, Pernambuco, Piauí, Rio Grande do Norte e Sergipe.

Os comentários sobre a distribuição geográfica e hábitats das espécies foram baseados nas informações contidas nos rótulos das exsicatas, nas observações feitas em campo e em dados de literatura (Mueller 1866, 1873; Rossignol et al. 1987; Webster 1955, 1956, 1957, 1958, 2001, 2002a,b, 2003; Santiago et al. 2006). São apresentadas ilustrações para a maioria das espécies, baseadas nos materiais estudados. Uma listagem completa das exsicatas analisadas é fornecida.

\section{Resultados e Discussão}

Na Região Nordeste do Brasil foram registradas 36 espécies do gênero Phyllanthus. Estas são comumente herbáceas e, menos freqüentemente, arbustivas ou arbóreas. Dentre as espécies arbóreas, foram encontradas: Phyllanthus acuminatus, $P$. chacoensis, $P$. gradyi, $P$. octomerus e $P$. juglandifolius.
O padrão de ramificação das espécies pode ser: a) não filantóide, com ramos persistentes e variadamente ramificados, encontrados em 12 das espécies estudadas ou; b) filantóide, com ramos em geral decíduos, plagiotrópicos e dispostos espiraladamente ao longo do ramo principal ou de suas ramificações, encontrado na maioria das espécies (24) (Fig. 1a, b). Neste último caso, os ramos podem ser pinatiformes (Fig. 1a), semelhantes a uma folha composta pinada, ou bipinatiforme (Fig. 1b), semelhantes a uma folha bipinada. Os ramos, às vezes, podem ser modificados em filocládios (Fig. 1c) e entre as espécies brasileiras são encontrados apenas na seção Choretropsis, onde podem ser achatados ( $P$. angustissimus, $P$. edmundoi, P. flagelliformis, $P$. gladiatus, $P$. klotzschianus e $P$. scoparius) ou cilíndricos a subcilíndricos ( $P$. choretroides e $P$. spartioides) e portarem ou não folhas desenvolvidas (Fig. 2a). As folhas são sempre simples, em geral membranáceas com margens planas (a maioria das espécies) ou revolutas ( $P$. retroflexus) (Fig. 3e). Catafilos estão presentes na inserção dos ramos das espécies com padrão de ramificação filantóide (Fig. 1d). As inflorescências são unissexuais ou bissexuais, geralmente cimosas (tirsiformes em $P$. chacoensis e $P$. juglandifolius) e mais raramente fasciculadas ( $P$. gradyi) ou racemosas ( $P$. almandensis). Flores solitárias são encontradas nas terminações dos ramos em $P$. niruri, $P$. minutulus, $P$. stipulatus e $P$. lindbergii ou na base, como em $P$. urinaria. As flores em Phyllanthus são monoclamídeas com 4 a 6 sépalas, estas unisseriadas na maioria das espécies, excetuando $P$. acuminatus, $P$. brasiliensis, $P$. edmundoi, $P$. gladiatus e $P$. scoparius, onde são bisseriadas. As sépalas possuem cores esbranquiçadas, amareladas ou esverdeadas, mais raramente, vináceas. Os estames são em número de 2 a 6, livres a unidos, com anteras de deicência desde longitudinal a vertical. Androceu formado por dois estames é encontrado em $P$. choretroides, $P$. minutulus e $P$. gradyi; com quatro em $P$. chacoensis (Fig. 1r) e P. octomerus, cinco em $P$. tenellus (Fig. 3n), quatro a seis em $P$. juglandifolius e três nas demais espécies. As flores estaminadas possuem discos (exceto em $P$. chacoensis), comumente segmentados (íntegro 
em $P$. gradyi), alternissépalos e extremamente diversificados quanto à forma. $\mathrm{O}$ disco pistilado, ao contrário do estaminado, é usualmente íntegro variando de anelar a cupuliforme e, mais raramente, segmentado como em P. heteradenius (Fig. 2h). O ovário é 3-carpelar, 3-locular e 2-ovulado por lóculo, exceto $P$. chacoensis, cujo ovário é 2- locular e 1-ovulado. Os frutos são em geral capsulares, mais raramente drupáceos $(P$. chacoensis). As sementes são geralmente trígonas (Fig. 1e), menos freqüentemente plano-convexas, como em P. acuminatus (Fig. 1f), ou reniformes, como em $P$. juglandifolius (Fig. 1g) com testa esculturada ou lisa.

\section{Chave para as espécies de Phyllanthus da Região Nordeste}

1. Plantas com ramos modificados em filocládios.

2. Filocládios achatados em seção transversal.

3. Plantas dióicas.

4. Pedicelo pistilado subcilíndrico; sépalas da série externa do cálice ovais; estiletes bífidos; estigmas agudos; sementes verruculosas 17. P. gladiatus

4'. Pedicelo pistilado triangular; sépalas da série externa do cálice obovais; estiletes bilobados; estigmas obtusos; sementes reticuladas

14. P. edmundoi

3'. Plantas monóicas.

5. Folhas desenvolvidas presentes em todos os estádios de desenvolvimento da planta; estames livres; flores de ambos os sexos longo pediceladas (pedicelo de 2,5-8 mm compr. 15. P. flagelliformis

5'. Folhas escamiformes ou, quando, desenvolvidas, apenas no estádio inicial do desenvolvimento; estames unidos; flores de ambos os sexos subsésseis ou curtopediceladas (pedicelo até $1,5 \mathrm{~mm}$ compr.)

6. Flores com 5 sépalas unisseriadas; disco das flores estaminadas com segmentos pateliformes 22 P. klotzschianus

6'. Flores com 6 sépalas bisseriadas; disco das flores estaminadas com segmentos globosos.

7. Flores pistiladas com disco constituído por segmentos cilíndricos; estigmas agudos

4. $P$. angustissimus

7'. Flores pistiladas com disco pateliforme, com margens ligeiramente crenadas; estigmas obtusos

35. P. scoparius

2'. Filocládios cilíndricos a subcilíndricos em seção transversal.

8. Estames 2; anteras com rimas horizontais

11. P. choretroides

8'. Estames 3; anteras com rimas oblíquas .

34. P. spartioides

1'. Plantas com ramos não modificados em filocládios.

9. Folhas com base assimétrica.

10. Folhas sésseis a subsésseis (pecíolo até $1 \mathrm{~mm}$ compr.), com ápice subtruncado....

9 P. carvalhoi

10'. Folhas pediceladas (pecíolo > que $1 \mathrm{~mm}$ compr.), com ápice arredondado a agudo.

11. Folhas com margens hispídulas próximo à base; estames completamente unidos; sépalas 6; frutos bulados

36. P. urinaria

11'. Folhas com margens lisas; estames livres a parcialmente unidos; sépalas 5; frutos lisos.

12. Estames parcialmente unidos; disco estaminado com superfície papilosa ... 26. P. niruri

12'. Estames livres; disco estaminado com superfície lisa.

13. Lâmina foliar 1-1,7 cm compr.; anteras com tecas divergentes pelo conectivo espessado; pedicelo pistilado 3-4 mm compr.; estiletes unidos em coluna 30. P. sincorensis 
13'. Lâmina foliar 1,9-5,5 cm compr.; anteras com tecas não divergentes; pedicelo pistilado $1,8-3 \mathrm{~cm}$ compr.; estiletes livres 20. P. hypoleucus

9'. Folhas com base simétrica.

14. Folhas opostas; flores em racemos terminais

2. P. almadensis

14'. Folhas alternas; flores em címulas, tirsos ou solitárias e axilares.

15. Estames 2, 4-6 ou 5

16. Estames 2 ou 5.

17. Estames 5; sementes com testa minutamente escamiforme ... 33. P. tenellus

17 '. Estames 2; sementes com testa estriada ou areolada 18

18. Ervas com até $20 \mathrm{~cm}$ alt., lâmina foliar 2,6-5,1 $\mathrm{mm}$ compr., membranácea; estames unidos; disco pistilado segmentado; sementes estriadas

25. P. minutulus

18'. Árvores com até $6 \mathrm{~m}$ alt.; lâmina foliar 3,8-8 cm compr., cartácea; estames livres, voltados um para o outro; disco estaminado cupuliforme; sementes areoladas

16. P. gradyi

16'. Estames 4 ou 4-6.

19. Flores estaminadas de uma mesma inflorescência com estames variando de 4-6; anteras cordiformes com rimas oblíquas a sub-horizontais

21. P. juglandifolius

19'. Flores estaminadas de uma mesma inflorescência sempre com 4 estames; anteras oblongóides com rimas verticais.

20. Disco ausente em ambas as flores; ovário 2-locular; frutos drupáceos .....

10. P. chacoensis

20'. Disco presente em ambas as flores; ovário 3-locular; frutos capsulares ...

22. P. octomerus

15'. Estames 3.

21. Sépalas $5 \mathrm{em}$ ambas as flores.

22. Estames unidos.

23. Címulas bissexuais dispostas em toda a extensão dos ramos; sépalas com ápice cuspidado; anteras com rimas oblíquas 3 P. amarus

23' Címulas unissexuais estaminadas dispostas da base até mais da metade do comprimento dos ramos; sépalas com ápice arredondado; anteras com rimas verticais ou horizontais.

24. Plantas sem aerênquima; lâmina foliar estreitamente elíptica; anteras com rimas verticais

24 P. lindbergii

24'. Plantas com aerênquima próximo à base do caule; lâmina foliar oblonga a oblongo-elíptica; anteras com rimas horizontais

31. P. stipulatus

22'. Estames livres.

25. Segmentos do disco estaminado elípticos, de ápice caudado ou falcado; sépalas pistiladas cartáceas; pedicelo pistilado 1,7-2 $\mathrm{mm}$ compr., cilíndrico

19. P. heteradenius

25'. Segmentos do disco estaminado obtriangulares, de ápice agudo; sépalas pistiladas membranáceas; pedicelo pistilado ca. 1,2 cm compr., filiforme

32. P. subemarginatus

21'. Sépalas $6 \mathrm{em}$ ambas as flores.

26. Cálice bisseriado.

27. Lâmina foliar com ápice arredondado; disco estaminado 6-segmentado

23. P. lacteus 
27'. Lâmina foliar com ápice abruptamente acuminado, agudo ou cuspidado; disco estaminado íntegro ou 3-segmentado.

28. Ramos jovens indumentados; lâmina foliar com ápice abruptamente acuminado; disco estaminado 3-segmentado 1. P. acuminatus

28'. Ramos jovens glabros; lâmina foliar com ápice agudo ou cuspidado; disco estaminado íntegro

7. P. brasiliensis

26'. Cálice unisseriado.

29. Plantas dióicas; folhas subcoriáceas; estames unidos em coluna..... 18. P. gongyloides

29'. Plantas monóicas; folhas membranáceas ou cartáceas; estames livres.

30. Caule em geral com ramos arranjados em zigue-zague; folhas com margem fortemente revoluta.

29. P. retroflexus

30'. Caule com ramos retos; folhas com margem plana.

31. Ramos papilosos; anteras com rimas verticais

31'. Ramos glabros; anteras com rimas horizontais.

5. P. bahiensis

32. Lâmina foliar 9,7-12,6×3,3-4 cm compr:; pedicelo pistilado 15,4-15,6 cm compr. no estádio de frutificação; fruto 9-10 mm diâm.

12. P. cladotrichus

32'. Lâmina foliar 0,6-1,6 × 1,2-1,5 cm compr.; pedicelo pistilado 0,6-1,5 cm compr. no estádio de frutificação; fruto 1,5-2 mm diâm.

33. Plantas herbáceas até $0,5 \mathrm{~m}$ alt.

34. Lâmina foliar orbicular ou oblata; sépalas estaminadas ovais a ovalelípticas e pistiladas oblongas a lineares; pedicelo do fruto ca. 6 mm compr., cilíndrico

28. P. orbiculatus

34'. Lâmina foliar elíptica a largamente elíptica, elíptico-oboval a oboval; sépalas estaminadas obovais e pistiladas espatuladas; pedicelo do fruto ca. $2 \mathrm{~mm}$ compr., clavado .... 8. P. caroliniensis subsp. caroliniensis

33'. Plantas arbustivas com $0,8-1,6 \mathrm{~m}$ alt.

35. Anteras com tecas não divergentes; sépalas pistiladas ca. $2 \mathrm{~mm}$ compr.

6. P. blanchetianus

35'. Anteras com tecas divergentes; sépalas pistiladas ca. $1 \mathrm{~mm}$ compr.

13. P. claussenii

1. Phyllanthus acuminatus Vahl, Symb. Bot.: 95. 1791.

Fig. 1 h-i

Exclusiva das Américas, ocorrendo desde a porção norte do México até o norte da Argentina incluindo Antilhas (Webster 2003; Silva \& Sales 2007). No Brasil está associada às florestas úmidas perenifólias, estacionais litorâneas e também de altitudes, às matas de restingas e às matas de galeria dos cerrados das Regiões Norte, Centro-Oeste, Nordeste e Sudeste. No Nordeste, ocorre da Bahia à Paraíba, crescendo sobre solos argilosos, nas bordas das florestas de terras baixas ("matas atlânticas") voltadas para o litoral e nas de altitudes ("brejos de altitude" ou "matas serranas").

Material selecionado: BRASIL. PERNAMBUCO: Águas Belas, 19.XI.2004, fl.efr., M. J.Silva 572 (PEUFR).
2. Phyllanthus almadensis Müll. Arg., Fl. bras. 11(2): 28. 873.

Espécie endêmica da Bahia. Cresce na região cacaueira nos limítrofes de Ilhéus e Itabuna, em solos argilosos, em ambientes úmidos e sombreados.

Material selecionado: BRASIL. BAHIA: Itabuna, bairro PedroJerônimo, 18.X.1980, fl., T.S. Santos3614(CEPEC).

3. Phyllanthus amarus Schum. \& Thonn., Kongl. Dasnke Vidensk. Skr. 4: 195. 1829.

Fig. $1 \mathrm{j}$

Espécie cosmopolita. No Brasil distribui-se em todas as regiões, crescendo em todos os tipos de vegetação, em ambientes úmidos, perturbados ou ainda como ruderal ou invasora em áreas cultivadas. No Nordeste, ocorre em todos os 
estados, em solos arenosos ou areno-argilosos, sendo ainda comum em jardins, como ruderal e em áreas cultivadas.

Material selecionado: BRASIL. PERNAMBUCO: Alagoinha, 9.IV.2002, fl. e fr., M. J. Silva \& J. I. Melo 172 (PEUFR).

\section{Phyllanthus angustissimus Müll. Arg.,} Linnaea 32 (4): 55.1863.

Fig. 1 k-1

Espécie endêmica do Brasil e com distribuição disjunta, sendo encontrada na Bahia, Minas Gerais e Rio Grande do Sul. No Nordeste, é referida apenas na Bahia onde habita solos paludosos, dos campos rupestres da Chapada Diamantina e os arenosos de matas de restinga. Material selecionado: BRASIL. BAHIA: Palmeiras, no Morro do Pai Inácio, do lado oposto da torre de repetição, 12²7'35"S, 41²6'25"W, 900 m elev., 29.VII.1994, fl. e fr., A. Pereira et al. 248 (HUEFS).

5. Phyllanthus bahiensis Müll. Arg., Linnaea 32 (4): 20. 1863.

Fig. $1 \mathrm{~m}-\mathrm{n}$

Espécie conhecida da Bahia a Sergipe, onde cresce em matas secundárias litorâneas (Floresta Atlântica) ou higrófila densa, como as de Ilhéus, em ambientes úmidos sobre solos argilosos.

Material selecionado: BRASIL. BAHIA: Entre Rios, $11^{\circ} 56$ 'S, 3805'W, 4.XII.2001, fl. e fr., M. L Guedes et al. 7379 (HUEFS).

6. Phyllanthus blanchetianus Müll. Arg., Linnaea 32 (4): 38.1863.

De acordo com Webster (2002b), esta espécie é endêmica da Bahia, sendo pouco conhecida e não mais recoletada desde seu estabelecimento. Material examinado: BRASIL. BAHIA: "Parte meridionale", "provinciae Bahia" J. S. Blanchet 3158 A (holótipo: G!, fotografia do holótipo: PEUFR!).

\section{Phyllanthus brasiliensis (Aubl.) Poir., In:} Lam. Encycl. 5: 296. $1804 . \quad$ Fig. 1 o-p

Espécie ocorrendo no norte da América do Sul (Colômbia, sul da Venezuela, Peru e Brasil) (Webster 2003). No Brasil, é mais comum nas florestas baixas do Acre, Amapá, Amazonas e Roraima. Constitui nova referência no estado do Ceará.

Material examinado: BRASIL. CEARÁ: s.l., s.d., fl., Santos 236 (EAC).
8. Phyllanthus caroliniensis subsp. caroliniensis Walter, Flora Caroliniana: 228. 1788.

Fig. 1q

Espécie amplamente distribuída nas Américas, estendendo-se desde o sudeste dos Estados Unidos até a Argentina, incluindo Antilhas (Silva \& Sales 2007). No Brasil, distribui-se da Região Norte à Sul, crescendo na floresta atlântica, em cerrado (matas de galeria), caatinga e ainda nas florestas montanas ("brejos de altitudes"). No Nordeste, é encontrada desde as matas de restingas até as caatingas e cerrado. Ocorre geralmente associada a locais sombreados, úmidos ou parcialmente encharcados ou ainda em áreas cultivadas, como ruderal.

Material selecionado: BRASIL. PERNAMBUCO: Barreiros, 27.IX.2004, fl. e fr., M. J. Silva 555 (PEUFR).

9. Phyllanthus carvalhoi G.L. Webster, Lundellia 5: 15. 2002.

Conhecida apenas das matas higrófilas sul-baianas, localidade do tipo. Cresce em local úmido e sombreado.

Material examinado: BRASIL. BAHIA: Itamaraju, fazenda Pau Brasil, entrada no $\mathrm{km} 5$ rodovia Itamaraju/ Eunapólis na região da mata higrófila sul-baiana, 3.XI.1983, fl., A. M. Carvalho et al. 2022 (holótipo: CEPEC!).

10. Phyllanthus chacoensis Morong, Ann. New York Acad. Sci 7: 218. 1892. Fig. 1 r-s Espécie encontrada na Argentina, Brasil e Paraguai (Webster 1967; Silva \& Sales 2007). No Nordeste ocorre apenas na vegetação ripária, às margens do rio São Francisco, em solos arenosos ou areno-pedregosos, nos estados da Bahia e Pernambuco.

Material selecionado: BRASIL. BAHIA: Ipuaçú, Barragem de Bananeiras, 395'S, 12 39'W, 120 m alt., 3.VI.1980, fl., G. Pedra do Cavalo 361 (HRB).

11. Phyllanthus choretroides Müll. Arg., Linnaea 32(4): 52.1863.

Restrita aos campos rupestres dos estados de Minas Gerais e Bahia. Na Bahia, cresce em solos pedregosos, arenosos, ou em fendas de rochas e, ainda, nas margens de pequenos córregos nos campos rupestres da Chapada Diamantina, em altitudes de até $1.100 \mathrm{~m}$. 


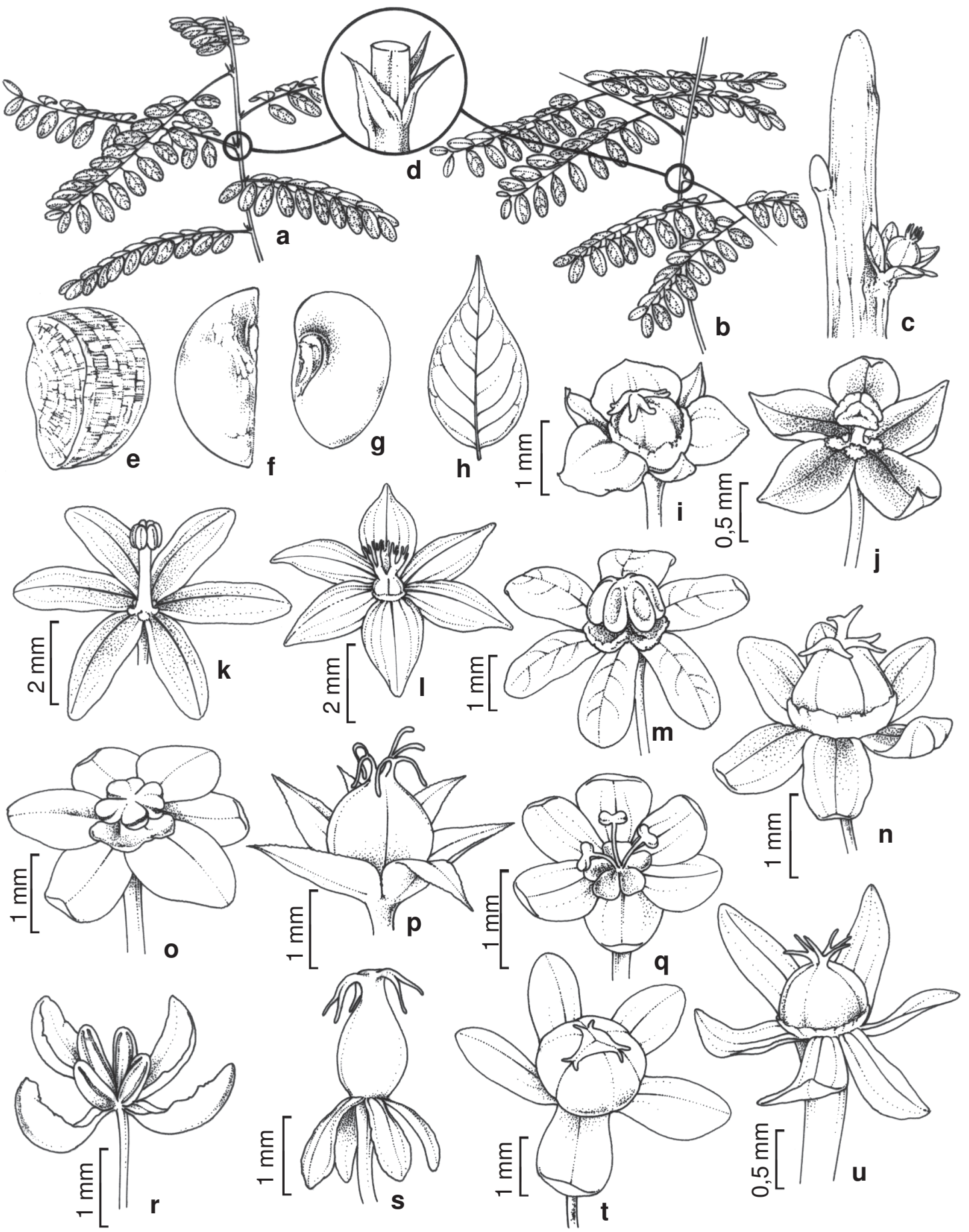

Figura 1 - a. Aspecto do padrão de ramificação filantóide com ramos pinatiformes; b. aspecto do padrão de ramificação filantóide com ramos bipinatiformes; c. ramo modificado em filocládio; d. catafilos; e. semente trígona; f. semente planoconvexa; g. semente reniforme. h-i. Phyllanthus acuminatus Vahl. - h. lâmina foliar; i. flor pistilada. j. P. amarus Schumm. \& Thonn. - j. flor estaminada. k-1. P. angustissimus Müll. Arg. - k. flor estaminada; 1. flor pistilada. m-n. P. bahiensis Müll. Arg. - m. flor estaminada; n. flor pistilada. o-p. P. brasiliensis Müll. Arg. - o. flor estaminada; p. flor pistilada. q. P. caroliniensis subsp. caroliniensis Walter. - q. flor estaminada. r-s. P. chacoensis Morong. - r. flor estaminada; s. flor pistilada. t. P. cladotrichus Müll. Arg. - t. flor pistilada. u. P. claussenii Müll. Arg. - u. flor estaminada. 
Material selecionado: BRASIL. BAHIA: Itambé, 12.I.1982, fl., N. Hensold et al. s.n (SPF 22298)

12. Phyllanthus cladotrichus Müll. Arg., Linnaea 32: 25. $1863 . \quad$ Fig. $1 \mathrm{t}$

Endêmica da Bahia. Habita a região da mata higrófila sul-baiana, no município de Ilhéus, e o centro-litoral da Bahia, no município de Cachoeira, ao longo dos rios Paraguaçu e Jacuípe.

Material selecionado: BRASIL. BAHIA: Ilhéus, Zona da Sapucaeira, fazenda São José, 17.III.1999, fr., L. A. Mattos Silva et al. 3903 (HUEFS).

13. Phyllanthus claussenii Müll. Arg., Linnaea 32: 40. 1863.

Fig. $1 \mathrm{u}$

Endêmica do Brasil, ocorrendo nas Regiões Nordeste, Sudeste, Centro-Oeste e Sul. No Nordeste, cresce em vegetação de cerrado, campo rupestre, carrasco e caatinga, nos estados da Bahia, Ceará, Paraíba e Pernambuco (Webster 2002b; Silva \& Sales 2003, 2007), associada a diferentes tipos de solos.

Material selecionado: BRASIL. PERNAMBUCO: Arcoverde, Serra das Varas, 2.VII.2004, fl. e fr., M. J. Silva 450 (PEUFR).

14. Phyllanthus edmundoi Santiago, Bradea 5(2): 44. 1988.

Endêmica a uma área do município de Lençóis, estado da Bahia, onde cresce em vegetação arbustiva, próxima de ambientes lacustres.

Material examinado: BRASIL. BAHIA: Lençóis, entre $8-10 \mathrm{~km}$ a noroeste da cidade, na estrada para Barro Branco, $12^{\circ} 32^{\prime}$ S, $41^{\circ} 20^{\prime} \mathrm{W}$, s.d., fl. e fr., G. P. Lewis et al. 923 (holótipo: CEPEC!).

15. Phyllanthus flagelliformis Müll. Arg., Linnaea 32(4): 54. 1863.

Fig. 2 a-c

Espécie, até o momento, restrita aos estados de Alagoas e Bahia. Habita ambientes abertos dos campos rupestres, sobre solos arenosos e úmidos, próximo a depressões adjacentes às matas de encosta, em afloramentos rochosos na Bahia. Em Alagoas, é encontrada em vegetação de restinga.

Material selecionado: BRASIL. BAHIA: Lençóis,

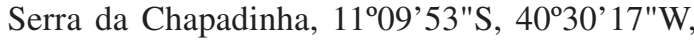
6.IV.1996, fl. e fr., M. L Guedes et al. 2868 (HRB).
16. Phyllanthus gradyi M. J. Silva \& M. F. Sales, Novon 16: 421. 2006.

Fig. $2 \mathrm{f}$

Espécie restrita ao Nordeste do Brasil, onde ocorre nos estados de Alagoas, Bahia e Pernambuco. Cresce nas florestas de terras baixas e montanas ("brejos de altitude"), em altitudes de 800-900 m, em Pernambuco; nas florestas montanas e submontanas ("Serra da Pedra Lascada"), em altitudes de 600-900 m, na Bahia, e nas de terras baixas, em Alagoas, em trechos sombreados, sobre solos argilosos recobertos por serrapilheira.

Material selecionado: BRASIL. PERNAMBUCO: AbreueLima, 15.XI.2004, fl. efr., M. J. Silva \& A. G Silva 556 (holótipo: PEUFR!, isótipos: SP!,UEC!,IPA!, INPA!).

17. Phyllanthus gladiatus Müll. Arg., Linnaea 32(4): 52.1863.

No Nordeste é encontrada apenas no sul da Bahia, crescendo tanto nas bordas quanto no interior de matas. Também foi encontrada na costa litorânea do Espírito Santo, onde habita a vegetação de restinga, sobre solos arenoargilosa ou próxima de capoeirões, em solos argilosos (Santiago et al. 2006).

Material selecionado: BRASIL. BAHIA: Itacaré, $\mathrm{km}$ 49 da rodovia Ilhéus/Itacaré cerca de $11 \mathrm{~km}$ ao norte do povoado de Serra Grande, 25.VI.1998, fl., L. A. Mattos Silva et al. 3781 (ALCB).

18. Phyllanthus gongyloides Cordeiro \& Carneiro-Torres, Bot. J. Linn. Soc. 146: 247. 2004.

Fig. 2 d-e

Espécie provavelmente endêmica dos campos rupestres da Chapada Diamantina, na Bahia. Cresce em solos areno-pedregosos ou pedregosos próximos a fendas de rochas, nos municípios de Campo Formoso, Morro do Chapéu e Pindobaçu.

Material selecionado: BRASIL. BAHIA: Morro do Chapéu, Ferro Doido, 17.V.1975, fl., A. L. Costa \& G. M. Barbosa s.n. (ALCB 3563).

19. Phyllanthus heteradenius Müll. Arg., in Mart, Fl. bras. 11(2): 63. 1873. Fig. 2 g-h Espécie endêmica das Regiões Nordeste e Sudeste (Minas Gerais) do Brasil. No Nordeste está associada à vegetação de caatinga dos estados de Alagoas, Bahia, Paraíba, Pernambuco 

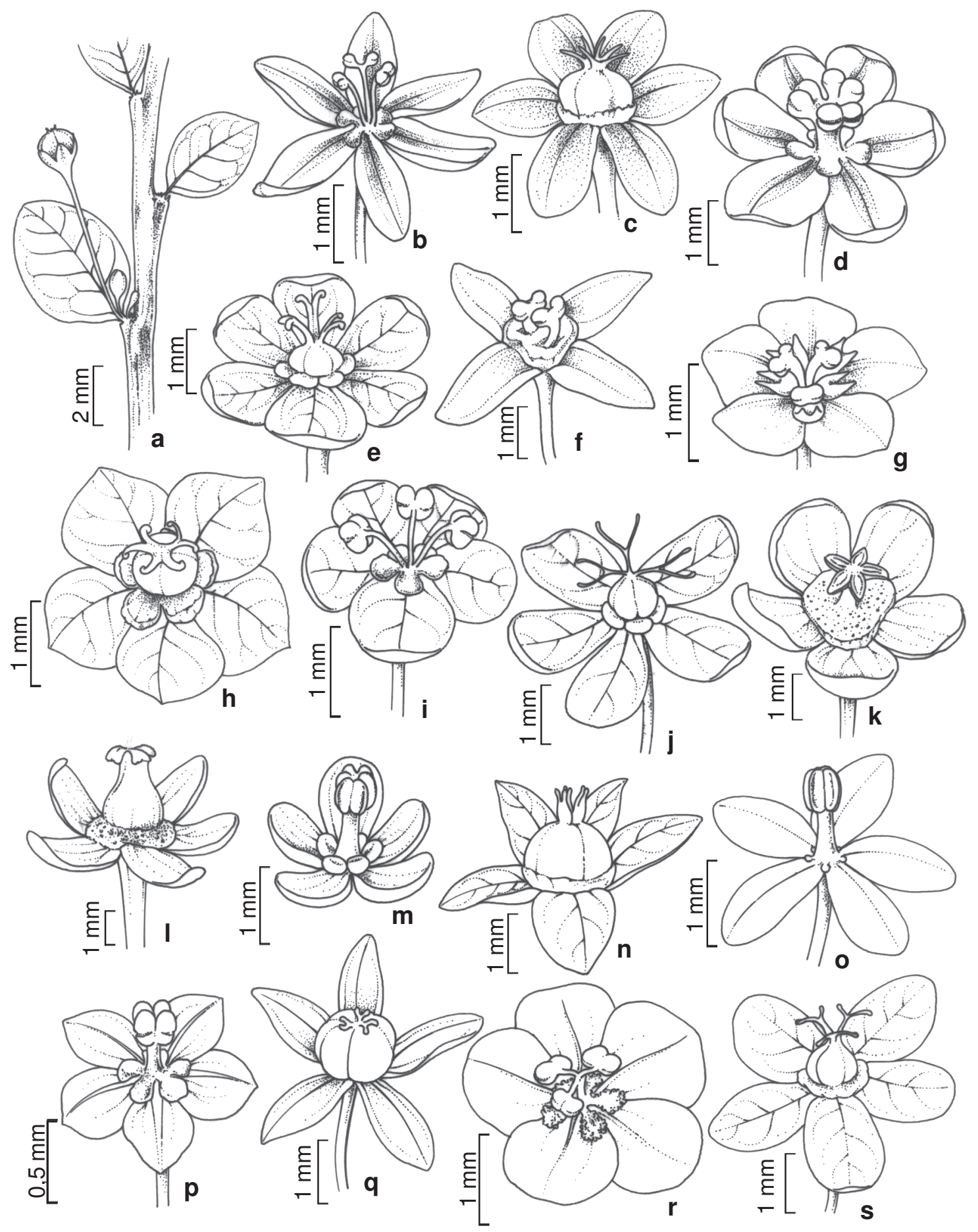

Figura 2 - a-s. Phyllanthus flagelliformis Müll. Arg. - a. filocládio com folha desenvolvida; b. flor estaminada; c. flor pistilada. d-e. P. gongyloides Cordeiro \& Carneiro-Torres. - d. flor estaminada; e. flor pistilada. f. P. gradyi M.J.Silva \& M. F. Sales. - f. flor estaminada. g-h. P. heteradenius Müll. Arg. - g. flor estaminada; h. flor pistilada. i-j. P. hypoleucus Müll. Arg. - i. flor estaminada; j. flor pistilada. k-1. P. juglandifolius Willd. - k. flor estaminada; 1. flor pistilada. m-n. P. klotzschianus Müll. Arg. - m. flor estaminada; n. flor pistilada. o. P. lindbergii Müll. Arg. - o. flor estaminada. p-q. P. minutulus Müll. Arg. - p. flor estaminada; q. flor pistilada. r-s. P. niruri L. - r. flor estaminada; s. flor pistilada. 
e Sergipe, aos tabuleiros baianos e às dunas litorâneas do Rio Grande do Norte. Habita preferencialmente locais abertos e sombreados, sobre solos arenosos, areno-pedregosos ou areno-argilosos.

Material selecionado: BRASIL. PERNAMBUCO: Brejo da Madre de Deus, 14.II.2004, fl. e fr., M. J. Silva et al. 383 (PEUFR).

20. Phyllanthus hypoleucus Müll. Arg., Linnaea 32: 40.1863.

Fig. 2 i-j

Ocorre apenas no Brasil, nos estados do Espírito Santo, Bahia e Pernambuco (Silva \& Sales 2007). Distribui-se desde o nível do mar até $1.000 \mathrm{~m}$ de altitude (Webster 2002b), exclusivamente no interior ou subosque de matas secundárias.

Material selecionado: BRASIL. PERNAMBUCO: Vicência, Mata do Engenho Canavieira, 26.VIII.2002, fl. e fr., M. J. Silva 201 (PEUFR).

21. Phyllanthus juglandifolius Willd., Enum. Hort. Berol. Suppl. 64. $1813 . \quad$ Fig. 2 k-1

Ocorre, predominantemente, associada às florestas secundárias das porções norte e leste da América do Sul, na Bolívia, Brasil, Equador, Guiana Francesa, Peru, Trindad e Tobago e Venezuela (Standley \& Steyermark 1949; Webster 1956; Gillespie 1993). No Brasil distribui-se nas Regiões Norte (Pará, Rondônia), Nordeste (Bahia, Maranhão, Paraíba, Pernambuco) e Sudeste (Minas Gerais, Rio de Janeiro), em ambientes de borda e no interior de matas, em trechos alagadiços ou rochosos. Material selecionado: BRASIL. BAHIA: Dom Macedo da Costa, Fazenda Mocambo, 1256'S, 39¹0'W, 31.V.1985, fr., L. R. Noblick \& Lemos 3814 (HUEFS).

22. Phyllanthus klotzschianus Müll. Arg., Linnaea 32: 53. 1863.

Fig. 2 m-n

Espécie brasileira com distribuição nos estados de Alagoas, Bahia, Espírito Santo, Goiás, Minas Gerais, Pernambuco, Rio de Janeiro, Sergipe e São Paulo (Silva \& Sales 2007). Habita ambientes de matas de restingas até a Caatinga, incluindo os campos rupestres e carrascos, geralmente habitando fendas de rochas areníticas ou solos arenosos.
Material selecionado: BRASIL. BAHIA: Mucugê, acima do Povoado de Guiné, 1245'34"S, 41³0’35"W, $1.508 \mathrm{~m}$ alt., 13.III.2007, fl. e fr., M. J. Silva et al. 984 (UEC).

23. Phyllanthus lacteus Müll. Arg., Linnaea 32(4): 52.1863.

Registrada apenas para o município de Maráu, Bahia, onde cresce em ambientes úmidos e sombreados, sobre solos argilosos próximos à costa litorânea no sul do estado.

Material selecionado: BRASIL. BAHIA: Maráu, no km 71 da estrada de Ubaitaba para Ponte do Mutá em direção ao sítio São Marcos, 2.II.1983, fl., A. M. Carvalho \& T. Plowman 1407 (CEPEC).

24. Phyllanthus lindbergii Müll. Arg., Fl. bras. 11(2): 35.1873.

Fig. 2 o

Ocorre nos estados de Minas Gerais, Tocantins, Goiás e Bahia, em cerrados (campos limpos e sujos) e veredas. Na Bahia, é registrada apenas nos municípios de Correntina e Barreiras, crescendo próximo a veredas, em solos paludosos. Material selecionado: BRASIL. BAHIA: Correntina, 13³1'30"S, 45²2'05"W, 26.VII.1995, fl. e fr., $R$. C. Mendoça et al. 2381 (IBGE).

25. Phyllanthus minutulus Müll. Arg., Fl. bras. 11(2): 54. 1874.

Fig. 2 p-q

Espécie sul-americana que se distribui no Brasil, Colômbia, Guiana e Venezuela (Webster 1956, 2002b; Silva \& Sales 2007). No Brasil, ocorre em todas as Regiões, nos diversos tipos de vegetação (Silva \& Sales 2007). No Nordeste, é comumente encontrada nas florestas litorâneas, restingas e matas de galeria em cerrado. Habita, preferencialmente, ambientes úmidos e sombreados, sobre solos arenosos e argilosos.

Material selecionado: BRASIL. BAHIA: Andaraí, próximo a Igatu, $12^{\circ} 53^{\prime} 52^{\prime \prime S}, 41^{\circ} 18^{\prime} 45^{\prime \prime} \mathrm{W}$, 5.II.1999, fl. e fr., E. M. Silva et al. 58 (HUEFS).

26. Phyllanthus niruri L., Sp. pl. 2: 981.1753.

Fig. 2 r-s

Apresenta distribuição americana, ocorrendo dos Estados Unidos até a Argentina, incluindo Antilhas (Webster 1970). No Brasil, distribui-se em todas as Regiões. No Nordeste, 
ocorre em locais úmidos e sombreados ou, como ruderal, associada ao cerrado, caatinga, mata de galeria, campos rupestres e na floresta atlântica litorânea ou montana.

Material selecionado: BRASIL. BAHIA: Lençóis, próximo ao rio Santo Antônio, $12^{\circ} 39^{\prime} \mathrm{S}, 41^{\circ} 19^{\prime} \mathrm{W}$, 380 m, 29.I.1997,fl. efr., B. Stannard et al. 4645 (HUEFS).

27. Phyllanthus octomerus Müll. Arg., Fl. bras. 11 (2): 30.1874.

Espécie endêmica do estado da Bahia, sendo conhecida apenas da coleção Martius s.n., referida por Mueller (1874), na Flora brasiliensis. Neste estudo não foi observada em campo, nem examinada a coleção-tipo. Mesmo assim, optou-se por considerar as informações de Mueller (1874) e referi-la entre as demais estudadas. A espécie diferencia-se bastante das demais co-genéricas, principalmente por possuir ovário 4-locular, flores estaminadas com oito sépalas e pistiladas com dez sépalas.

28. Phyllanthus orbiculatus L.C. Rich., Act. Soc. Hist. Nat. Paris 1: 113. 1792. Fig. 3 a-b Apresenta distribuição sul-americana (Brasil, Bolívia, Paraguai, Colômbia, Venezuela, Guianas, Peru e Trindad e Tobago) (Silva \& Sales 2007; Gillespie 1993; Webster 1956). No Brasil ocorre da Região Norte à Sudeste, nos estados de Alagoas, Bahia, Piauí, Ceará, Goiás, Mato Grosso, Mato Grosso do Sul, Minas Gerais e São Paulo, em vários tipos de vegetação como cerrado, campo rupestre, caatinga, florestas atlântica e amazônica. No Nordeste, ocorre principalmente nos cerrados, campos rupestres e matas estacionais, crescendo tanto em solos areno-pedregosos, quanto nos argilosos.

Material selecionado: BRASIL. BAHIA: Abaíra, estrada de Abaíra no sentido de Piatã, 13²1' 52 "S, $41^{\circ} 45^{\prime} 27^{\prime \prime} \mathrm{W}, 22 . \mathrm{III} .1999$, fl. e fr., R. M. Harley et al. 5361 (HUEFS).

29. Phyllanthus retroflexus Brade, Arch. Jardim Botânico do Rio de Janeiro 15: 8. 1957.

Fig. 3 c-e

Ocorre apenas no Brasil, nos estados da Bahia e Espírito Santo. Cresce em campos rupestres com afloramentos graníticos, na Bahia, em altitude variando de 577-800 m e em florestas montanas, no Espírito Santo.

Material selecionado: BRASIL. BAHIA: Castro Alves, Serra da Jibóia, 1251'11"S, 39²8'19"W, 22.XII.1992, fl., L. P. Queiroz \& T. S. N. Sena 2985 (HUEFS).

30. Phyllanthus sincorensis G.L. Webster, Lundellia 5: 15. 2002.

Embora seja conhecida apenas da localidade tipo, na Serra do Sincorá na Bahia, (Webster 2002b), esta espécie provavelmente pode ser encontrada no complexo de serras circunvizinhas à Cordilheira do Sincorá, como a do Gobira, do Guiné, da Tesoura, do Mochambongo e da Capa, devido à semelhança edafoclimática, vegetacional e altitudinal.

Material examinado: BRASIL. BAHIA: Campos Gerais, região da Serra do Sincorá entre Brejão e Iracema, 18.II.1943, fl. e fr., R. L. Fróes 20172 (holótipo: US!).

31. Phyllanthus stipulatus (Raf.) Webster, Contr. Gray. Her. 176: 53. $1955 . \quad$ Fig. 3j-k

Ocorre desde o sudeste dos Estados Unidos, incluindo Antilhas, até a Região Sul do Brasil. $\mathrm{Na}$ Região Nordeste, habita especialmente ambientes florestais litorâneos, em locais comumente paludosos, sobre solos hidromórficos (Webster 1970, 2002b), nos estados da Bahia, Alagoas e Pernambuco.

Material selecionado: BRASIL. PERNAMBUCO: Belém de Maria, 4.VI.2003, fl. e fr., M. J. Silva 339 (PEUFR).

32. Phyllanthus subemarginatus Müll. Arg., Linnaea 32(4): 39. $1863 . \quad$ Fig. $31-m$

Ocorre apenas no Brasil, nos estados da Bahia, Pernambuco, Rio de Janeiro, Santa Catarina e São Paulo (Silva \& Sales 2007), crescendo principalmente na porção leste do país. No Nordeste, é comumente encontrada ao longo da floresta atlântica e montana, em locais úmidos e sombreados, sobre latossolo vermelho-amarelo, com serrapilheira. 


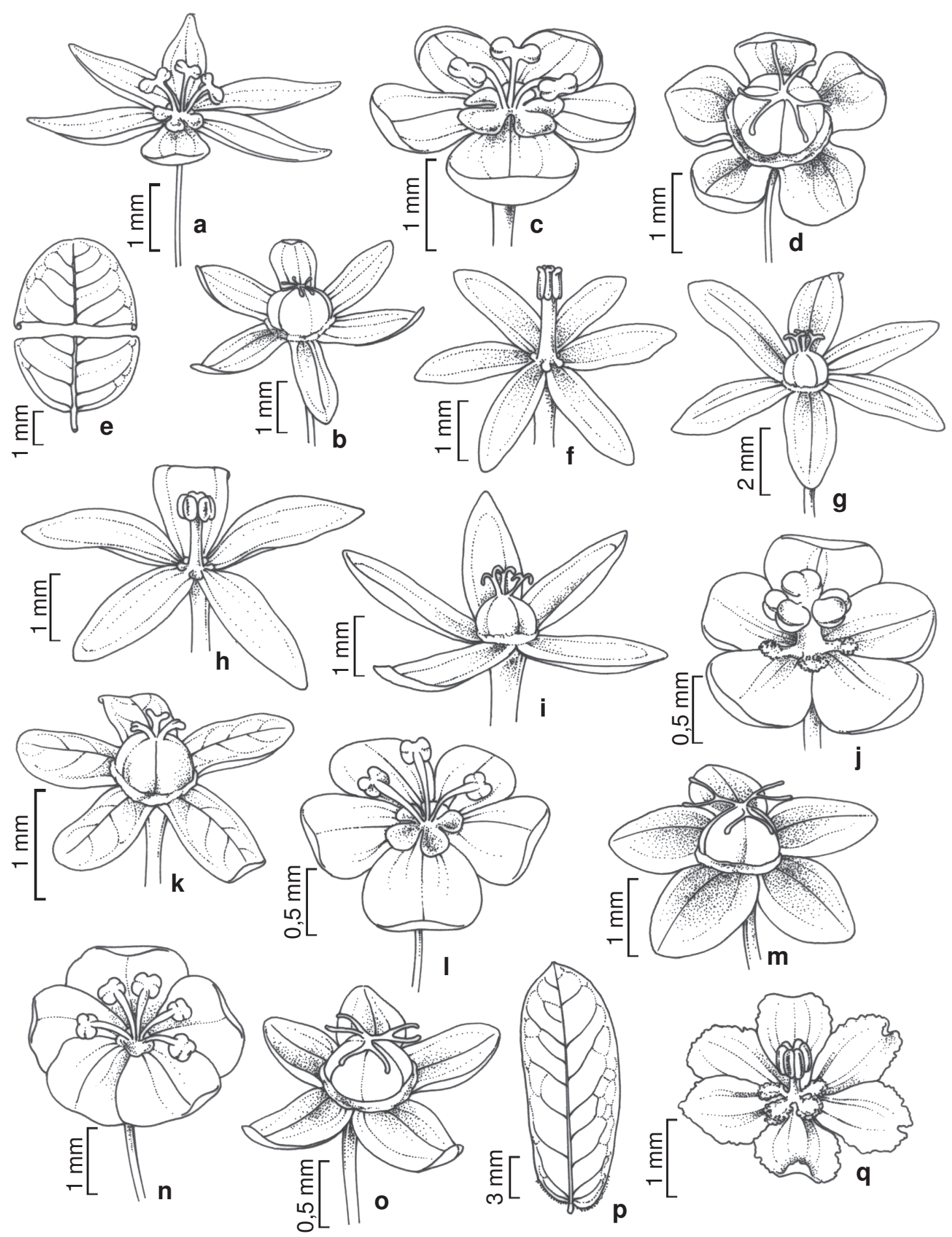

Figura 3 - a-q. Phyllanthus orbiculatus L.C. Rich. - a. flor estaminada; b. flor pistilada. c-e. P. retroflexus Brade - c. flor estaminada; d. flor pistilada; e. lâmina foliar com margem revoluta. f-g. P. scoparius Müll. Arg. - f. flor estaminada; g. flor pistilada. h-i. P. spartioides Müll. Arg. - h. flor estaminada; i. flor pistilada. j-k. P. stipulatus (Raf.) Webster. - j. flor estaminada; k. flor pistilada. 1-m. P. subemarginatus Müll. Arg. - 1. flor estaminada; m. flor pistilada. n-o. P. tenellus Roxb. - n. flor estaminada; o. flor pistilada. p-q. P. urinaria L. - p. lâmina foliar; q. flor estaminada. 
Material selecionado: BRASIL. PERNAMBUCO: Taquaritinga do Norte, mata da Microonda, 16.IV.2005, fl. e fr., M. J. Silva et al. 643 (PEUFR).

33. Phyllanthus tenellus Roxb., Flora Indica 2(3): 668. 1882.

Fig. 3 n-o

Espécie pantropical, de acordo com Webster (1956; 1970). No Brasil ocorre da Região Norte à Sul. No Nordeste, é freqüentemente encontrada desde as matas litorâneas até a vegetação de caatinga e no cerrado e, ainda, como invasoras de culturas e jardins.

Material selecionado: BRASIL. PERNAMBUCO: Garanhuns, 19.XI.2004, fl. e fr., M. J. Silva \& J. I. Melo 584 (PEUFR).

34. Phyllanthus spartioides Pax \& Hoffm., Repert Spec. Nov. Regni Veg. Bd. 19: 174. 1923.

Fig. 3 h-i

Espécie com distribuição nas Regiões Nordeste (Bahia), Centro-Oeste (Goiás) e Sudeste (Minas Gerais). Cresce em ambientes úmidos, paludosos ou próximos a matas de galeria em cerrados e campo rupestres, em altitudes entre 1.000-1.700 m. Na Região Nordeste ocorre somente na Bahia, onde é comumente encontrada crescendo em ambientes úmidos, sobre solos arenosos nos campos rupestres da Chapada Diamantina.

Material selecionado: BRASIL. BAHIA: Rio de Contas, trilha para o Pico das Almas, 15'31'37"S, 415'01"W, 1.795 m elev., 2.III.1999, fl. e fr., E. Melo et al. 2630 (HUEFS).

35. Phyllanthus scoparius Müll. Arg., Fl. bras. 11(2):14. 1873. Fig. $3 \mathrm{f}-\mathrm{g}$

Encontrada apenas na Cadeia do Espinhaço, nos estados de Minas Gerais e Bahia. Cresce entre fendas de rochas e em solos arenosos e úmidos ou, também, nas áreas campestres, com populações de gramíneas e ciperáceas, em solos úmidos, entre altitudes de 700-1.400 m.

Material selecionado: BRASIL. BAHIA: Mucugê, encosta da serra na subida para o Pico do Gobira, 24.I.2000, fl., L. P. Queiroz et al. 5646 (HUEFS).
36. Phyllanthus urinaria L., Sp. pl. 1: 982. 1753.

Fig. 3 p-q

Espécie cosmopolita (Rossignol et al. 1987). No Nordeste, é registrada nos estados da Bahia e Pernambuco, crescendo, em geral, nas bordas de ambientes florestais litorâneos, em locais úmidos e sombreados, sobre solos argilosos ou, como invasora, em culturas e jardins.

Material selecionado: BRASIL. PERNAMBUCO: Igarassu, 16.X.2002, fl. e fr., M. J. Silva 243 (PEUFR).

\section{Conclusões}

Das 36 espécies de Phyllanthus ocorrentes no Nordeste, três apresentam distribuição pantropical (Phyllanthus amarus, $P$. tenellus e $P$. urinaria), três são amplamente distribuídas do sul dos Estados Unidos até Argentina (P. caroliniensis, $P$. niruri e $P$. stipulatus) e as 30 espécies restantes são principalmente sul-americanas, 24 das quais exclusivas do Brasil.

No Nordeste do Brasil, o estado da Bahia destaca-se por apresentar o maior número de espécies de Phyllanthus (35), distribuídas especialmente nos campos rupestres que compõem a Chapada Diamantina e em áreas de caatingas, seguido de Pernambuco (17) onde as espécies ocorrem principalmente nas caatingas hipoxerófilas e florestas montanas situadas entre as subzonas do agreste e sertão. A menor representatividade nos demais estados pode ser consequiência de um menor esforço de coleta, ou ainda, da carência de botânicos taxonomistas.

Estudos abordando grupos taxonômicos da flora do Nordeste são escassos, porém tornam-se imprescindíveis, uma vez que através do conhecimento do potencial florístico de uma determinada região pode-se, além de avaliar o estado de conservação das espécies e de suas áreas de ocorrências, fornecer subsídios para estudos ecológicos e de conservação. 


\section{Lista de Exsicatas}

Agra, F. 1649 (1), 642 (13); Albuquerque 615 (7); Alves, M. 2308 (22); Anderson 9224 (19); Aparecida 4031 (25); Árborcz 6328 (25), 188 (31); Atkins 4827 (28); Barbosa, M. R. 2664 (13); Barreto 9764 (13); Bastos, S. K. M. 2 (29); Bautista, H. 1648 (1); Belém 2501 (22); Blanchet, J. S. 3158a (6); Brade A. C. 19329 (29), 11107 (32); Branch 2 (28); Brito 57 (3); Budziak 47 (36); Cantarelli 488 (1), 432 (1); Carneiro, T. (26); Carvalho, A. M. 972 (4), 2022 (9), 1407 (23); Carvalho 741 (1), 71 (3), 82 (32); Cavalcanti 111 (28); Cavalo 56 (3), 361, 533 (10); Conceição 453 (28); Coons 77-283 (22); Cordeiro 9245 (11); Cortês 36 (28), Davidse 11872 (15); Davidson 10693 (31); Ehringhaus, C. 51 (21); Eiten 1019, 10279 (3), 9065 (8), 4965 (19), 10907 (22), 10703 (26), 10076 (28), 6261 (32), 7875 (33); Emmerich, M. 2856 (32); Falkenberg 798 (32), 4797 (33); Farias 220 (32); Farney 318 (22); Félix 2650 (22); Fernandes 61, 62 (26); Ferraz, E. 598 (16); Ferreira 489 (15); Figueiredo 179 (26); Filho 5 (26); Fonseca 1852, 3095 (28); Fortius 3367 (8), 652 (10), 3965 (26); Fróes, R. L. 20172 (30); Ganev, W. 1751, 3081 (12), 1058, 2347 (15), 443 (22); Gillespie 879 (1); Giulietti, A. M. 1488 (4); Glaziou 19824, 15447a (11); Graham 394 (21); Grisi 112 (3); Guedes, M. L. 41 (1), 1407 (4), 7379 (5), 5216 (13), 2868, 5476 (15); Harley, R. M. 22525 (4), 2832, 15393, 24353, 27739, 50325 (15), 19499, 24473 (34); Hatschbach, G. 28715, 49497 (22); Heringer, E. P. 805 (3), 155 (19), 6075 (25), 480, 805 (26), 4072 (28), 3527 (31), 5927, 6710 (33); Irwin 17576 (3), 23961 (8), 2149 (8), 28949, 21164 (22), 21186, 28648 (25), 8931, 17808, 27235 (28), 16826, 17534 (31); Júnior 2042 (28); Krapovickas 45628 (10); Krause, L. 112 (26), 67 (32); Kuhlmann 83 (33); Laurênio, A. 1823 (13), 735, 2022 (19); Lemos 59 (26); Lewis, G. P. 923 (14); Lima, A. 50-576 (1), 66-4537, 73-7285 (1), 55-2213, 66-4537 (3), 9754 (15), 50-454 (16), 51-906, 53-4678 (21), 51-779 (22), 2521 (26), 716735 (32); Lira 178 (1); Lyra, S. 4071 (22); Lopes 375 (20); Lowe 3985 (33); Lucena, M. F. 132 (1), 811 (16), 56 (32); Luceño 486 (31); McDowell 1919 (31); Maas, P. 3411, 7092 (32); Magalhães 16908 (22); Marcon, A. 58 (32); Marcondes 97 (25); Martins 117 (26); Mattos, L. A. 3903 (12), 3781 (17); Mayo 1002 (16), 1037 (32); Melo, E. 2630 (34); Mendonça, R. C. 2381 (24); Mexia 5394 (1), 4332 (26); Mezena 1 (33); Millinkin 2279 (31); Ming 348 (3), 350 (36); Miranda, A. M. 985 (26); Miranda-Silva, E. 120 (15); Mori 4530 (15); Mota 21 (1); 1077 (1); Moura 779 (19), 443 (25); Nelson 1117 (36); Noblick 1484 (8), 3814 (21), 3211 (29); Oldenburger 1277 (21); Oliveira, M. 790 (1), 771 (3); 779 (8), 710 (16); Paula 1028 (26); Peña 87 (26); Pereira, A. 248 (4); Pickel, B. 1274 (1), 1962 (3), 662 (8), 11 (16), 1275 (21), 289 (26); Pimentel, R. 37, 48 (32); Pinto 28 (21); Pirani, J. R. 1902 (22); Plowman, T. 10071 (12), 12063 (31); Pontual, I. 77 (PEUFR);
Queiroz, L. P. 4336 (19), 2985, 6399 (29), 5646 (35); Ramalho 190 (10); Ramesh 54 (3); Ratter (1); Reitz 3479 (8), 2539 (32), 3283 (36); Rocha 199 (36); Sales, M. F. 644 (26), 207, 400, 464 (32); Santana 428 (5); Santos, T. S. 3614 (2), 3931 (33); 3932 (36); Schinini, A. 8031 (10); Silva, M. J. 117, 150, 189, 199, 572, 625 (1); 119, 128, 172, 159, 215, 230, 234, 248, 274, 301, $311,318,334,340,402,414,428,482,534,570,573$, 580 (3), 108, 254, 286, 305, 335, 341, 350, 410, 417, 480, 491, 555, 561 (8), 450 (13), 305, 556, 557, 558, 559, 540, 542, 545 (16), 106, 127, 165, 383, 395 (19), 201 (20), 502 (22), 115, 346 371, 536 (25), 103, 109, 127, 190, 191, 247, 317, 343, 344, 465, 489, 451, 529, 569, 626 (26), 300, 320, 478 (28), 111, 133, 217, 279, 285, 323, 339, 384 (31), 137, 140, 141, 144, 146, 147, 148, 188 (32), 138, 233, 419, 560, 579, 584, 749 (33), 243, 322, 356 (36); Silva, T. 60 (21); Silva 242 (1), 440 (8), 817 (19); 58 (25), 434 (32), 629 (33); Smith 1420 (8); Soares, R. 11 (3), 10 (33); Souza, V. 10181 (22); Souza 4 (15); Stork 10487 (7); Stranghetti 97 (1); Strudwick 4167 (8); Sucre 3418 (32); Tavares 421 (19); Teixeira 1464 (21); Tsuda 3 (3); Torezam, J. M. 522 (32); Valverde 143 (1); Vidal 232 (26), 7 (32); Vieira 102 (19), 116 (25); Webster, G. L. 25727 (15), 1989 (26), 25434 (32); Zarucchi 2774 (8).

\section{Agradecimentos}

Aos curadores dos herbários aqui listados pelo empréstimo do material. Ao CNPq, pela concessão da bolsa de mestrado (130108/2004-9). Ao Programa de Pós-graduação em Botânica da Universidade Federal Rural de Pernambuco, pelo apoio logístico dispensado e aos consultores ad hoc pelas valiosas sugestões.

\section{REFERÊNCIAS BIBLIOGRÁFICAS}

Carneiro-Torres, D. S.; Cordeiro, I. \& Giulietti, A. M. 2003. O gênero Phyllanthus L. (Euphorbiaceae) na Chapada Diamantina, Bahia, Brasil. Acta Botanica Brasilica 17: 267-280.

Chase, M. W.; Zmartzty, S.; Lledó, M. D.; Wurdack K. J.; Swesen, S. M. \& Fay, M. F. 2002. When in doubt, put it in Flacourtiaceae: a molecular phylogenetic analysis based on plastid $r b c L$ DNA sequences. Kew Bulletin 57: 141-181.

Cordeiro, I. 1992. Euphorbiaceae na Flora da Serra do Cipó, Minas Gerais. Boletim de Botânica da Universidade de São Paulo 13: 169-217. 
1995. Euphorbiaceae. In: Stannard, B. L. Flora of the Pico das Almas, Chapada Diamantina, Bahia - Brasil. Royal Botanic Garden, Kew. Pp.300-317.

Gillespie, L. J. 1993. Euphorbiaceae of the Guianas: annotated species checklist and key to the genera. Brittonia 45(1): 56-94.

Holmgren, P. K.; Holmgren, N. H. \& Barnett, L. C. 1990. Index Herbariorum, part 1: the herbaria of the world. New York Botanical Garden, New York, 693p.

Hunter, J. T. \& Bruhl, J. J. 1997. Two new species of Phyllanthus and notes on Phyllanthus and Sauropus (Euphorbiaceae: Phyllantheae) in New South Wales. Telopea 7(2):149-165.

Kathriarachchi, H.; Samuel, R.; Hoffmann, P.; Mlinarec, J.; Wurdack, K. J.; Ralimanana, H.; Stuessy, T. \& Chase, M. W. 2006. Phylogenetics of tribe Phyllantheae (Phyllanthaceae; Euphorbiaceae sensu lato) base on $n r I T S$ and platid matK DNA sequence data. American Journal of Botany 93(4): 637-655.

Mueller, J. A. 1866. Euphorbiaceae (Except Euphorbieae). In: De Candolle, A. Prodromus systematis naturalis regni vegetabilis 15(2): 189-1286. Victor Masson, Paris.

1873. Euphorbiaceae. Phyllanthus. In: Martius, C. F. P. \& Eichler, A.G. (eds.). Flora brasiliensis. F. Fleischer, Lipsiae, v.15, pars 2. Pp. 24-76.

Rossignol, L.; Rossignol, M. \& Haicour, R. 1987. A systematic revision of Phyllanthus subsection Urinaria (Euphorbiaceae). American Journal of Botany 74(12): 1853-1862.

Samuel, R.; Kathriarachchi, H.; Hoffmann, P.; Barfuss, M. H. J.; Wurdack, K. J.; Davis, C. C. \& Chase, M. W. 2005. Molecular phylogenetics of Phyllanthaceae: evidence from plastid MATK and nuclear PHYC sequences. Americal Journal of Botany 92: 132-141.

Santiago, L. J. M; Louro, R. P. \& Emmerich, M. 2006. Phyllanthus section Choreropsis in Brazil. Botanical Journal of the Linnean Society 150: 131-164.

Silva, M. J. \& Sales, M. F. 2004. O gênero Phyllanthus L. (Phyllantheae Euphorbiaceae Juss.) no bioma caatinga do estado de Pernambuco. Rodriguésia 54(84): 105-130. $\&$ 2007. Phyllanthus L. (Phyllanthaceae) em Pernambuco. Brasil. Acta Botânica Brasílica 21(1): 79-98.

Smith, L. B. \& Downs, R. J. 1959. Resumos preliminares das Euphorbiáceas de Santa Catarina. Sellowia 11: 155-231.

Standley, P. C. \& Steyermark, J. A. 1949. Flora of Guatemala. Fieldiana Botany 24(6): 25-171.

Ulysséa, M. \& Amaral, L. G. 1997. Contribuição ao estudo do gênero Phyllanthus (Euphorbiaceae) ocorrente na ilha de Santa Catarina, Brasil. Insula 26: 1-28.

Webster, G. L. 1955. Studies of the Euphorbiaceae, Phyllanthoideae. I. Taxonomic notes of the West Indian species of Phyllanthus. Contribuitions of the Gray Herbarium of the Haward University 176: 45-60. 1956. A monographic study of the West Indian species of the Phyllanthus L. Journal of the Arnold Arboretum 37(2): 91-122, 217-256, 341-357. 1957. A monographic study of the West Indian species of the Phyllanthus L. Journal of the Arnold Arboretum 38: 51-79, 170-198, 295-375.

1958. A monographic study of the West Indian species of the Phyllanthus L. Journal of the Arnold Arboretum 39: 49-100, 111-212.

1967. The genera of the Euphorbiaceae in the Southeastern United States. Journal of the Arnold Arboretum 48(3): 303-361. 1970. Revision of the Phyllanthus (Euphorbiaceae) in the continental United States. Brittonia 22: 44-76.

2001. Synopsis of Croton and Phyllanthus (Euphorbiaceae) in Western Tropical Mexico. Contribuition University 
of Michigan Herbarium. Ann Arbor 33: 353-388.

2002a. Three new sections and a new subgenus of Phyllanthus (Euphorbiaceae). Novon 12: 290-298.

2002b. A synopsis of the Brazilian taxa of Phyllanthus section Phyllanthus (Euphorbiaceae). Lundelia 5: 1-26.
2003. A synopsis of Phyllanthus section Nothoclema (Euphorbiaceae). Lundelia 6: 19-36.

Wurdack, K. J. Molecular systematics and evolution of Euphorbiaceae sensu lato. 2002. PhD Thesis. University of North Carolina, Chapel Hill, USA. 